\title{
Cobalamin status in sickle cell disease
}

\author{
O.I. Ajayi ${ }^{1}$, S. Bwayo-Weaver ${ }^{2}$, S. Chirla ${ }^{1}$, M. Serlemitsos-Day ${ }^{2}$, M. Daniel $^{1}$, M. Nouraie ${ }^{1}$, K. \\ Edwards $^{2}$, O. Castro ${ }^{1}$, F. Lombardo ${ }^{1}$, and V.R. Gordeuk ${ }^{3}$ \\ ${ }^{1}$ Howard University Hospital, 2041 Georgia Ave N.W, Washington, D.C, USA 20060 \\ ${ }^{2}$ Howard University College of Pharmacy, $23004^{\text {th }}$ Street N.W, Washington, D.C, USA, 20059 \\ ${ }^{3}$ University of Illinois at Chicago, 820 South Wood St., Chicago, IL, USA, 60612
}

\begin{abstract}
Background-Some studies comparing serum cobalamin in individuals with and without sickle cell disease (SCD) have suggested a higher prevalence of cobalamin deficiency in SCD but others have not. Our aim was to prospectively compare cobalamin status in African-Americans with and without SCD.
\end{abstract}

Methods-We analyzed blood samples from 86 subjects in 2 groups; SCD $(n=29)$ and non$\operatorname{SCD}(n=57)$. Serum cobalamin, folate, homocysteine, methylmalonic acid (MMA), anti-intrinsic factor antibody, helicobacter pylori antibody and gastrin were measured and compared.

Results-The median cobalamin was $235 \mathrm{pmol} / \mathrm{L}$ in the SCD group versus $292 \mathrm{pmol} / \mathrm{L}$ in the non-SCD group (p-value $=0.014$ ). No significant differences in MMA or homocysteine were seen. Using the criteria of a low cobalamin and an elevated MMA or an elevated MMA alone, cobalamin deficiency was suggested in $4(13.8 \%)$ in the SCD group and $6(10.5 \%)$ in the nonSCD group. Two of these SCD patients and 4 of these control subjects had chronic renal disease, which may lead to elevated MMA in the absence of cobalamin deficiency. The remaining 4 met criteria for cobalamin deficiency, $2(6.9 \%)$ in the SCD group and 2 (3.5\%) in the non-SCD group $(\mathrm{p}=0.6)$.

Conclusion-A lower cobalamin was observed in SCD patients without a higher prevalence of cobalamin deficiency. The inclusion of haptocorrin and holotranscobalamin measurement in future studies may provide a better assessment of cobalamin status in this patient group.

\section{Keywords}

sickle cell disease; cobalamin deficiency; vitamin B12; homocysteine; methylmalonic acid

\section{Introduction}

Sickle cell disease (SCD) is an inherited disorder of $\beta$-globin production in red blood cell precursors resulting in abnormal hemoglobin which polymerizes and causes red cell rigidity when deoxygenated. The clinical consequences are recurrent painful vaso-occlusive crises, hemolytic anemia and various potentially life threatening organ-system complications (Rees,

Correspondence: Olaide I. Ajayi, M.D., Department of Internal Medicine, Division of Hematology-Oncology, Howard University Hospital, 2041 Georgia Avenue N.W, Washington, DC, USA, 20060, Office: +1 301646 1922; Fax: +1 202865 1008; olaide.ajayi@gmail.com.

O.I. Ajayi contributed to the acquisition and analysis of data and writing of the paper. S. Bwayo-Weaver, M. Daniels and S.M. Nouraie contributed to data analysis and writing. O. Castro and S. Chirla contributed to the research design. M. Serlemitsos-Day and K. Edwards contributed to data analysis. F. Lombardo and V. Gordeuk contributed to the research design, revision and approval of the final paper. 
Williams \& Gladwin 2010). Cobalamin serves as cofactor for two important cellular enzymes - methylmalonyl coenzyme A mutase and methionine synthase, necessary for DNA synthesis (Randaccio, Geremia \& Demitri 2010). Manifestations of cobalamin deficiency include megaloblastic anemia and neuropsychiatric dysfunction. The prevalence of cobalamin deficiency in the general population is variable depending on the age, population studied and the criteria for diagnosis. (McLean et al. 2007) (Pfeiffer et al. 2005) (Campbell et al. 2003). It has been suggested that SCD poses a risk for cobalamin deficiency because of the increased demand from a high turnover of red blood cells (Osifo et al. 1983). Some studies have not found a significant decrease in serum cobalamin concentrations in SCD patients (Segal et al. 2004) (Lowenthal et al. 2000) while others have reported a significant decrease (Al-Momen 1995), and at least one study showed an increase in the mean cobalamin level (van der Dijs et al. 1998). In a previous retrospective study, we reported a significantly lower mean cobalamin concentrations in 105 African Americans with SCD compared to 112 African Americans without SCD (Kamineni et al. 2006).

Cobalamin deficiency has often been defined as a serum cobalamin concentration of less than $200 \mathrm{pg} / \mathrm{mL}$ (148 pmol/L) with limited sensitivity and specificity (Schneede \& Ueland 2005). Measurement of the metabolite methylmalonic acid (MMA) has a higher sensitivity and specificity for detecting cobalamin deficiency (Savage et al. 1994). MMA accumulates and is measurable in serum in cobalamin deficiency (Chatthanawaree 2011) but may also be elevated in chronic kidney disease and hypovolemic states (Savage et al. 1994). As cobalamin and folate are essential for the conversion of homocysteine to methionine, homocysteine also accumulates in cobalamin or folate deficiency. A low cobalamin concentration in the presence of normal MMA and homocysteine may not indicate cobalamin deficiency. This can be seen in deficiency of the cobalamin-binding protein haptocorrin (Carmel 2003), in HIV infection (Remacha \& Cadafalch 1999), in pregnancy (Metz et al. 1995) and with the use of oral contraceptives (Gardyn et al. 2000). An elevated MMA concentration in the presence of a normal cobalamin concentration may represent early biochemical and subclinical cobalamin deficiency in the absence of confounders. Cobalamin deficiency is likely in the presence of a low or normal cobalamin concentration and elevated MMA and homocysteine concentrations.

Recognizing early cobalamin deficiency in SCD may be difficult for several reasons. Firstly, the routine administration of folic acid in SCD can mask concurrent megaloblastic anemia, which can progress unrecognized to neurologic dysfunction that may be irreversible (Dhar, Bellevue \& Carmel 2003). Second, hydroxyurea, which is the mainstay of therapy in SCD, causes a predictable macrocytosis as part of its mechanism of action (Charache et al. 1992) mimicking cobalamin deficiency induced macrocytosis. In the present study, we compared serum cobalamin concentrations between African Americans with and without SCD in a prospective study. We also wished to determine the prevalence and manifestation of cobalamin deficiency by including measurements of MMA and homocysteine.

\section{Materials and Methods}

In this cross-sectional study, we enrolled African American subjects from a single teaching hospital. We measured cobalamin concentrations in a group of SCD patients and in a nonSCD group. We also investigated the functional cobalamin status of all individuals with measurements of serum MMA and homocysteine concentrations. Anti-intrinsic factor antibody, serum gastrin concentration and helicobacter pylori antibody were also measured to determine the etiology of any encountered cobalamin deficiency including pernicious anemia and helicobacter pylori related malabsorption. 
Patients aged 18 years or older with or without a previous diagnosis of SCD were eligible for this study. Exclusion criteria included a previous known diagnosis of cobalamin deficiency, current treatment with oral, intramuscular or subcutaneous cobalamin, severe illness, or malnutrition as determined by a body mass index below 18.5 . Non-critically ill inpatients, outpatient general medicine clinic patients, hospital and house staff were all eligible for enrollment. Subjects were recruited as SCD or as controls by medical history. Pregnancy and lactation were not exclusion criteria. Our previous report had shown a difference of $275 \mathrm{pmol} / \mathrm{L}$ in the mean serum cobalamin concentrations in African Americans with SCD compared to their non SCD counterparts (Kamineni et al. 2006). To detect such a difference at a two-sided significance level of 0.05 and a test power of $80 \%$ we planned a sample size of 75 in each group. We projected that approximately $60 \%$ of the subjects would be female. Howard University Institutional Review Board approval was obtained and the study protocol was approved by the ethics committee. The study was performed in accordance with the ethical standards laid down in the 1964 Declaration of Helsinki. Subjects provided written informed consent and underwent a history and physical examination and blood sampling.

Blood samples were processed at Howard University Hospital Clinical Laboratory and at Quest Diagnostic Laboratory, Baltimore, Maryland, USA and analyzed consecutively. The hemoglobin phenotype was confirmed by a high-pressure liquid chromatography hemoglobin fractionation method. Individual results were consistent with their assigned groups. The SCD group consisted of hemoglobin SS (HbSS), hemoglobin SC (HbSC) and hemoglobin $\mathrm{S}$ beta-thalassemia (HbS $\beta$ thal) subjects and the control group consisted of hemoglobin AA (HbAA), Hemoglobin AC (HbAC) and hemoglobin AS (HbAS) subjects. Serum concentrations of cobalamin, folate, homocysteine, MMA and gastrin were measured with normal reference ranges of $148-812 \mathrm{pmol} / \mathrm{L}$ for cobalamin, $>7.7 \mathrm{nmol} / \mathrm{L}$ for folate, $5.4-11.9 \mu \mathrm{mol} / \mathrm{L}$ for homocysteine, $87-260 \mathrm{nmol} / \mathrm{L}$ for MMA and $0-100 \mathrm{ng} / \mathrm{L}$ for gastrin. Anti-intrinsic factor and anti-helicobacter pylori immunoglobulin $\mathrm{G}$ antibody were assessed as either positive or negative. Renal function was estimated by measurement of serum creatinine with a normal reference range of $61.9-123.8 \mu \mathrm{mol} / \mathrm{L}$. A cobalamin concentration less than $148 \mathrm{pmol} / \mathrm{L}$ plus an elevated MMA concentration $(>260 \mathrm{nmol} / \mathrm{L})$ was regarded as possible cobalamin deficiency. Cobalamin deficiency was also likely in the presence of a normal cobalamin concentration and an elevated MMA. For statistical analysis, clinical and laboratory parameters were compared between the two groups and tested for statistical significance using the Chi square test for categorical variables and Student's t-test for continuous variables (after the best transformation to normal distribution). Analysis of covariance was used to adjust for the effect of age. A p-value of $<0.05$ was considered significant.

\section{Results}

Eighty six subjects were enrolled between July 2006 and December 2010 including 29 SCD (aged 20 to 57 years, male/female $=20 / 9$ ) and 57 non-SCD subjects (aged 22 to 72 years, male/female $=33 / 24$ ). Demographic characteristics of both groups are shown in Table 1. None of the females was pregnant or taking oral contraceptives at the time of enrollment. The median cobalamin concentration in the SCD group was lower compared with the control group at $235 \mathrm{pmol} / \mathrm{L}$ and $292 \mathrm{pmol} / \mathrm{L}$ respectively, with a difference of $57 \mathrm{pmol} / \mathrm{L}$ $(p$-value $=0.014)($ Table 2$)$. In the SCD group, the median (interquartile range) cobalamin concentrations in male and female subjects were $244(171-332) \mathrm{pmol} / \mathrm{L}$ and $224(196-$ 291) $\mathrm{pmol} / \mathrm{L}$ respectively $(\mathrm{p}$-value $=0.7)$. The median (interquartile range) cobalamin concentration for all male and female subjects was $271(216-391)$ pmol/L and $286(222-$ 429) $\mathrm{pmol} / \mathrm{L}$ respectively ( $\mathrm{p}$-value $=0.4)$. 
There was no significant differences found between the SCD and the non-SCD populations in MMA or homocysteine but a significantly higher folate concentration was observed in the SCD group with a median of $40.3 \mathrm{nmol} / \mathrm{L}$ versus $19.7 \mathrm{nmol} / \mathrm{L}$ (p-value <0.0001). All SCD patients were receiving daily oral folic acid compared to none in the control group. In subjects with a normal serum creatinine of $<88.4 \mu \mathrm{mol} / \mathrm{L}$, the median (interquartile range) of MMA was $109 \mathrm{nmol} / \mathrm{L}(79-134)$ for the SCD group and $113 \mathrm{nmol} / \mathrm{L}(82-145)$ for the control group. In both groups, there was a significant correlation between creatinine and MMA, the spearman correlation between creatinine and MMA in the SCD group $(n=25)$ was $0.59(\mathrm{P}=0.002)$ and in controls $(\mathrm{n}=41)$ was $0.41(\mathrm{P}=0.008)$. Adjusting for creatinine did not change the effect of SCD on cobalamin concentration. There was also a significantly lower gastrin concentration, with a median of $55 \mathrm{ng} / \mathrm{L}$ in the $\mathrm{SCD}$ group and $97 \mathrm{ng} / \mathrm{L}$ in the non-SCD group with a difference of $42 \mathrm{ng} / \mathrm{L}$ ( $\mathrm{p}$-value $=0.010$ ). After adjusting for the effect of age, gastrin remained lower in SCD patients with the geometric mean (SE) of 65 (1.2) ng/ $\mathrm{L}$ versus $97(1.1) \mathrm{ng} / \mathrm{L}$ in controls ( $\mathrm{p}$-value $=0.032$ ).

Ten subjects (11.6\%) met criteria for possible cobalamin deficiency defined by cobalamin concentration of less than $148 \mathrm{pmol} / \mathrm{L}$ and an elevated MMA concentration or by an elevated MMA alone. Of these, $4(13.8 \%)$ were in the SCD group and $6(10.5 \%)$ in the control group $(\mathrm{p}=0.8)$. The characteristics of these patients are shown in Table 3 . Nine of these 10 individuals had cobalamin concentrations above $148 \mathrm{pmol} / \mathrm{L}$ but had elevated MMA concentrations ranging from 271 to $922 \mathrm{nmol} / \mathrm{L}$. Cobalamin concentration could not be determined in the last one. All 4 SCD patients with possible cobalamin deficiency received daily folic acid and 3 received both folic acid and hydroxyurea. Six of these 10 subjects with elevated MMA had chronic kidney disease with elevated serum creatinine which is known to cause a high MMA making true cobalamin deficiency less likely. In the remaining 4 with normal renal function, $2(6.9 \%)$ in the SCD group and $2(3.5 \%)$ in the nonSCD group $(p=0.6)$, there was no other explanation for an elevated MMA, therefore they met criteria for cobalamin deficiency. There were no neuropsychiatric manifestations of cobalamin deficiency in any of the subjects based on a screening neurologic examination including assessment of mental status, motor, sensory and cranial nerves function and reflexes. Pernicious anemia was not diagnosed in any subject based on the absence of antiintrinsic factor antibody and a normal gastrin concentration. Eleven patients $(46 \%)$ in the SCD group had a positive IgG helicobacter pylori antibody compared with $20(41 \%)$ in the normal group (p-value $=0.7$ ), of these, 3 in the SCD group and 2 in the control group had a possibly low cobalamin status. A cobalamin concentration of less than $148 \mathrm{pmol} / \mathrm{L}$ was observed in 2 subjects in the SCD group and 1 in the control group and all 3 had MMA concentrations within the normal range suggesting that cobalamin deficiency was not present.

\section{Discussion}

This study supports previously published data and confirms that serum cobalamin is significantly lower in SCD patients (Al-Momen 1995) (Kamineni et al. 2006). Cobalamin deficiency was present in $6.9 \%$ of SCD patients in this study but the prevalence was not statistically different from the non-SCD group (3.5\%). The reason for the observed lower serum cobalamin concentration in the SCD group in the absence of a higher prevalence of functional cobalamin deficiency as indicated by a normal MMA and homocysteine is obscure. Inherited deficiency of the cobalamin-binding protein haptocorrin is a potential cause. Carmel reported a $15 \%$ prevalence of mild haptocorrin deficiency and a $0.6 \%$ prevalence of severe haptocorrin deficiency in patients with unexplained low serum cobalamin concentrations (Carmel 2003). However, Osifo reported higher haptocorrin concentrations in adult SCD patients (Osifo et al. 1989). Heterozygosity for a nonsense mutation $(315 \mathrm{C}>\mathrm{T})$ of the $T C N 1$ gene that is associated with haptocorrin deficiency was 
reported in a 32 year of black man with hemoglobin SS. A low cobalamin concentration (125 pmol/L) and normal MMA and homocysteine concentrations were seen in this patient (Carmel 2010).

Pernicious anemia was not diagnosed in any individual in this study. In pernicious anemia, an elevated serum fasting gastrin concentration and decreased serum pepsinogen I and cobalamin concentrations is usually seen(Lahner \& Annibale 2009). There was a lower serum gastrin concentration in the SCD group despite a lower serum cobalamin concentration further supporting the absence of pernicious anemia. There may be an age dependent increase in gastrin levels as the median age of the control group was 10 years higher than the median age of the SCD patients but age could not explain the lower gastrin level in SCD patient completely.

There are several limitations to this study. First, the sample size is small and the recruitment goal was not met. Second, measurements of haptocorrin and holotranscobalamin concentrations were not performed. Approximately one quarter of circulating cobalamin is bound to transcobalamin as holotranscobalamin, which is the functionally active cobalamin available for cellular metabolism. Holotranscobalamin is a marker of early cobalamin deficiency as holotranscobalamin concentration declines before total cobalamin. Holotranscobalamin measurement has been suggested as a better marker than total cobalamin for assessing cobalamin status (Nexo \& Hoffmann-Lücke 2011). Third, a trial of cobalamin therapy in the 10 patients with possible cobalamin deficiency was not undertaken.

\section{Conclusions}

In this study we have demonstrated that serum cobalamin is lower in SCD patients and most SCD patients in this study appeared to have adequate cobalamin status as evident by normal MMA and homocysteine concentrations but true cobalamin deficiency does exists in a small fraction. The cause of the observed lower serum cobalamin concentrations in SCD patients remains obscure and warrants further investigation. Elevated MMA concentrations found in about $14 \%$ of the SCD patients in this study may be partially explained by the presence of chronic kidney disease, this demonstrates the inadequacy of assessing cobalamin status in SCD with cobalamin, MMA and homocysteine levels alone. Additional studies in this population should include measurements of haptocorrin and holotranscobalamin.

\section{Acknowledgments}

We thank all the sickle cell patients who volunteered to participate in this study. This publication was made possible by Howard University's General Clinical Research Center grant \#2MO1-RR010284 from the National Center for Research Resources (NCRR), a component of the National Institutes of Health (NIH) and its contents are solely the responsibility of the authors and do not necessarily represent the official view of NCRR or NIH.

We also thank Hasan Ibrahim, M.D, Lawrence Momodu, Pharm.D, Adriana Medina, M.D., Shahla Gul Naoman, M.D., Hemamalini Karpurapu, M.D., Ramakrishna Chakilam, M.D, Bramara Godasi, M.D., Padma Kamineni, M.D. and Abraham Hollist for their various additional contributions to this study.

\section{References}

1. Al-Momen AK. Diminished vitamin B12 levels in patients with severe sickle cell disease. Journal of Internal Medicine. 1995; 237(6):551-5. [PubMed: 7782726]

2. Campbell AK, Miller JW, Green R, Haan MN, Allen LH. Plasma vitamin B-12 concentrations in an elderly Latino population are predicted by serum gastrin concentrations and crystalline vitamin B-12 intake. The Journal of Nutrition. 2003; 133(9):2770-6. [PubMed: 12949363]

3. Carmel R. Mild transcobalamin I (haptocorrin) deficiency and low serum cobalamin concentrations. Clinical Chemistry. 2003; 49(8):1367-74. [PubMed: 12881454] 
4. Carmel R, Bellevue R, Kelman Z. Low cobalamin levels associated with sickle cell disease: Contrasting origins and clinical meanings in two instructive patients. American Journal of Hematology. 2010; 85(6):436-9. [PubMed: 20309855]

5. Charache S, Dover GJ, Moore RD, Eckert S, Ballas SK, Koshy M, Milner PF, Orringer EP, Phillips G Jr, Platt OS. Hydroxyurea: effects on hemoglobin F production in patients with sickle cell anemia. Blood. 1992; 79(10):2555-65. [PubMed: 1375104]

6. Chatthanawaree W. Biomarkers of cobalamin (vitamin B12) deficiency and its applications. The Journal of Nutrition, Health and Aging. 2011; 15(3):227-31.

7. Dhar M, Bellevue R, Carmel R. Pernicious anemia with neuropsychiatric dysfunction in a patient with sickle cell anemia treated with folate supplementation. The New England Journal of Medicine. 2003; 348(22):2204-7. [PubMed: 12773647]

8. Gardyn J, Mittelman M, Zlotnik J, Sela BA, Cohen AM. Oral contraceptives can cause falsely low vitamin B12 levels. Acta Haematologica. 2000; 104(1):22-4. [PubMed: 11111117]

9. Kamineni P, Chirla S, Dinh K, Hasan S, Nidhiry E, Kwagyan J, Naab T, Lombardo F, Castro O, Dawkins F. Low Cobalamin levels in African Americans with and without sickle cell disease. Journal of the National Medical Association. 2006; 98(3):352-6. [PubMed: 16573298]

10. Lahner E, Annibale B. Pernicious anemia: new insights from a gastroenterological point of view. World Journal of Gastroenterology. 2009; 15(41):5121-8. [PubMed: 19891010]

11. Lowenthal EA, Mayo MS, Cornwell PE, Thornley-Brown D. Homocysteine elevation in sickle cell disease. Journal of the American College of Nutrition. 2000; 19(5):608-12. [PubMed: 11022874]

12. McLean ED, Allen LH, Neumann CG, Peerson JM, Siekmann JH, Murphy SP, Bwibo NO, Demment MW. Low plasma vitamin B-12 in Kenyan school children is highly prevalent and improved by supplemental animal source foods. The Journal of Nutrition. 2007; 137(3):676-82. [PubMed: 17311959]

13. Metz J, McGrath K, Bennett M, Hyland K, Bottiglieri T. Biochemical indices of vitamin B12 nutrition in pregnant patients with subnormal serum vitamin B12 levels. American Journal of Hematology. 1995; 48(4):251-5. [PubMed: 7717374]

14. Nexo E, Hoffmann-Lücke E. Holotranscobalamin, a marker of vitamin B-12 status: analytical aspects and clinical utility. The American Journal of Clinical Nutrition. 2011; 94(1):359S-365S. [PubMed: 21593496]

15. Norman EJ. Urinary methylmalonic acid test may have greater value than the total homocysteine assay for screening elderly individuals for cobalamin deficiency. Clinical Chemistry. 2004; 50(8): 1482-3. [PubMed: 15277369]

16. Osifo BO, Adeyokunnu A, Parmentier Y, Gerard P, Nicolas JP. Abnormalities of serum transcobalamins in sickle cell disease (HbSS) in Black Africa. Scandinavian Journal of Hematology. 1983; 30(2):135-40.

17. Osifo BO, Ehigie-Osifo EM, Parmentier Y, Gerard P, Nicolas JP. Serum unsaturated vitamin B12 proteins in adult patients with sickle cell anaemia (HbSS). Acta Haematologica. 1989; 81(3):11721. [PubMed: 2496559]

18. Pfeiffer CM, Caudill SP, Gunter EW, Osterloh J, Sampson EJ. Biochemical indicators of B vitamin status in the US population after folic acid fortification: results from the National Health and Nutrition Examination Survey 1999-2000. The American Journal of Clinical Nutrition. 2005; 82(2):442-50. [PubMed: 16087991]

19. Randaccio L, Geremia S, Demitri N, Wuerges J. Vitamin B12: unique metalorganic compounds and the most complex vitamins. Molecules. 2010; 15(5):3228-59. [PubMed: 20657474]

20. Rees DC, Williams TN, Gladwin MT. Sickle-cell disease. Lancet. 2010; 376(9757):2018-31. [PubMed: 21131035]

21. Remacha AF, Cadafalch J. Cobalamin deficiency in patients infected with the human immunodeficiency virus. Seminars in Hematology. 1999; 36(1):75-87. [PubMed: 9930570]

22. Savage DG, Lindenbaum J, Stabler SP, Allen RH. Sensitivity of serum methylmalonic acid and total homocysteine determinations for diagnosing cobalamin and folate deficiencies. The American Journal of Medicine. 1994; 96(3):239-46. [PubMed: 8154512] 
23. Schneede J, Ueland PM. Novel and established markers of cobalamin deficiency: complementary or exclusive diagnostic strategies. Seminars in Vascular Medicine. 2005; 5(2):140-55. [PubMed: 16047266]

24. Segal JB, Miller ER 3rd, Brereton NH, Resar LM. Concentrations of B vitamins and homocysteine in children with sickle cell anemia. Southern Medical Journal. 2004; 97(2):149-55. [PubMed: 14982264]

25. van der Dijs FP, Schnog JJ, Brouwer DA, Velvis HJ, van den Berg GA, Bakker AJ, Duits AJ, Muskiet FD, Muskiet FA. Elevated homocysteine levels indicate suboptimal folate status in pediatric sickle cell patients. American Journal of Hematology. 1998; 59(3):192-8. [PubMed: 9798656] 
Table 1

Demographic characteristics of all subjects

\begin{tabular}{|lcc|}
\hline Variable & SCD $(\mathbf{N}=\mathbf{2 9})$ & Non-SCD $(\mathbf{N}=\mathbf{5 7})$ \\
\hline Median interquartile age (yr) & $31(20-57)$ & $46(22-72)$ \\
\hline Sex - no.(\%) & & \\
\hline Male & $20(69)$ & $33(58)$ \\
\hline Female & $9(31)$ & $24(42)$ \\
\hline Hydroxyurea use (\%) & $18(62)$ & $0(0)$ \\
\hline Hemoglobin phenotype (\%) & & \\
\hline HbSS & $20(69)$ & $0(0)$ \\
\hline HbSC & $7(24)$ & $0(0)$ \\
\hline HbSßthal & $2(7)$ & $0(0)$ \\
\hline HbAA & $0(0)$ & $41(72)$ \\
\hline HbAS & $0(0)$ & $5(9)$ \\
\hline HbAC & $0(0)$ & $3(5)$ \\
\hline HbASathal & $0(0)$ & $1(2)$ \\
\hline Unknown & $0(0)$ & $7(12)$ \\
\hline
\end{tabular}

$\mathrm{Hb}=$ Hemoglobin, $\mathrm{SCD}=$ Sickle cell disease 


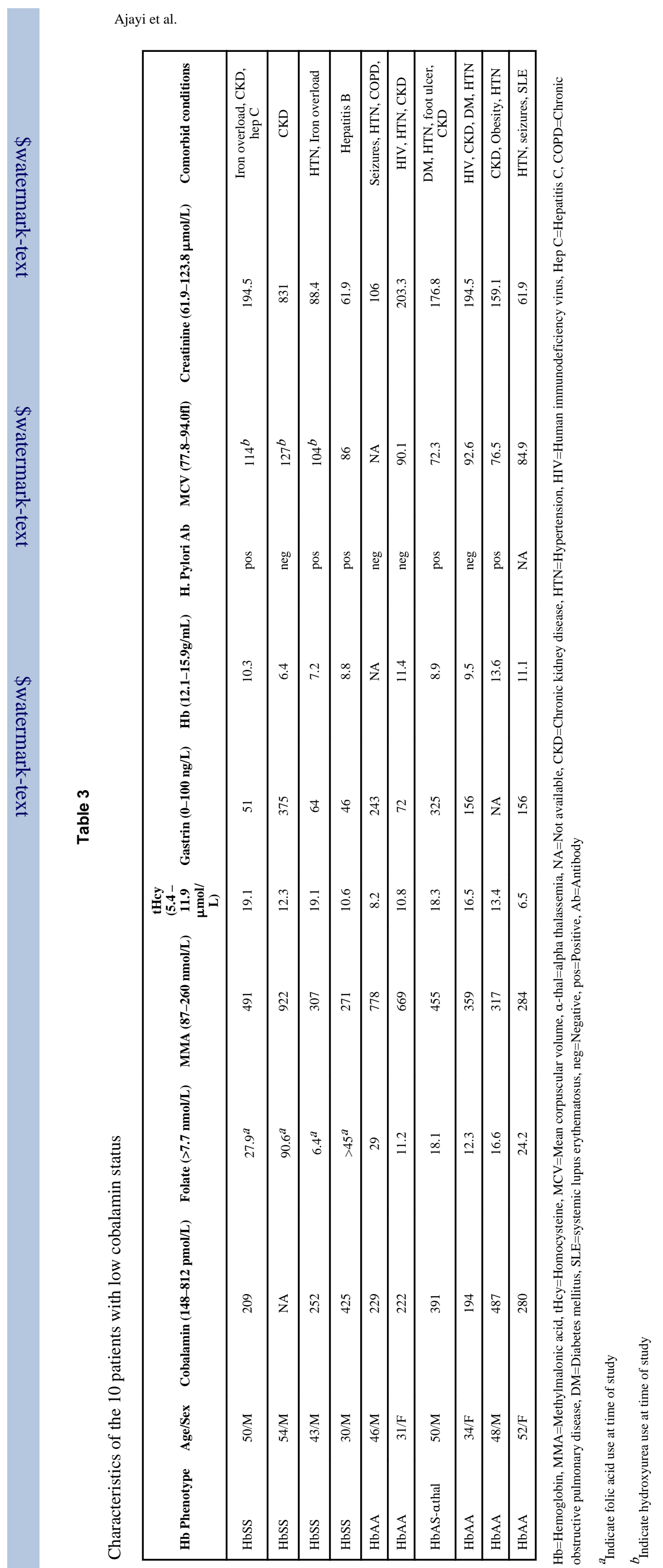

Page 10

Int J Lab Hematol. Author manuscript; available in PMC 2014 February 01. 